\section{Gérard Roizès}

Bertrand Marçais Yuri Yurov

\section{Les centromères des chromosomes de mammifères}

Les régions centromériques sont, pour partie, constituées de séquences d'ADN satellite dont l'une, l'ADN alpha satellite, semble jouer un rôle fonctionnel particulier. La structure physique commence à être élucidée; elle est variable d'un chromosome à l'autre et est le siège d'un polymorphisme tout à fait étonnant. Les contours des interactions ADN-protéines du complexe centromèrekinétochore apparaissent peu à peu. Mais on s'interroge toujours pour savoir pourquoi les régions centromériques restent compactes pendant tout le cycle cellulaire, pourquoi elles recombinent peu, si elles sont ou non pourvues de gènes... Les anomalies de fonctionnement des centromères, chez l'homme, sont associées à de nombreuses maladies (aneuploïdies, certains cancers...). Il reste, cependant, beaucoup plus de questions à résoudre qu'il n'y a de réponses déjà apportées.

\section{ADRESSE}

(; Roizès: directeur de recherche au Cnrs. B. Marçais : docteur de l'université. Y. Yurov chargé de recherche. Inserm U. 249 et Cinrs UPR 9())8, Institut de biologie, 4 , boulevard Henri-IV, 3406() Montpellier Cedex,

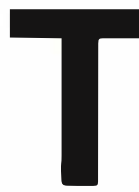

rois éléments sont indispensables pour que les chromosomes puissent se répliquer et ségréger normalement: des origines de réplication, des télomères et des centromères. I)es origines de réplication existent en grand nombre chez les mammifères et sont partiellement caractérisées [1]. Il en va de même pour les télomères [2]. I.es centromères sont, quant à eux, encore loin d'avoir livré leurs secrets malgré le nombre considérable d’études qui leur ont été consacrées dans les dernières années. Ils jouent pourtant un rôle essentiel dans la ségrégation correcte du matériel génétique au cours des générations et leur dysfonctionnement peut conduire à des anomalies chromosomiques importantes, dont la trisomie 21 est l'exemple le plus commu. Ia caractérisation moléculaire et fonctionnelle qui a été faite des centromères des chromosomes de la levure $S$. cerevisiae et, dans une moindre mesure, de $S$. pombe, permet d'espérer qu’il en sera bientôt de même pour les mammifères et, bien 
sûr, pour l'homme. Elle amènerait sans doute à comprendre beaucoup de phénomènes inexpliqués à ce jour, et permettrait peut-être d'envisager la construction de chromosomes artificiels de mammifères (MAC, mammalian artificial chromosomes), et en particulier humains, comme cela a déjà été réalisé chez. la levure (YAC; yeast artificial chromosomes). L'étude de la régulation des gènes humains dans un système homologue s'en trouverait grandement facilitée, et de tels chromosomes artificiels pourraient être utilisés à des fins de thérapie génique. En l'absence de commaissance de ce que sont les constituants moléculaires des centromères, leur définition ne peut se baser que sur l'observation des chromosomes au microscope: le centromère correspond à la constriction primaire que l'on peut observer à la métaphase de la mitose. Cette définition ne vaut pas pour tous les eucaryotes, puisque les

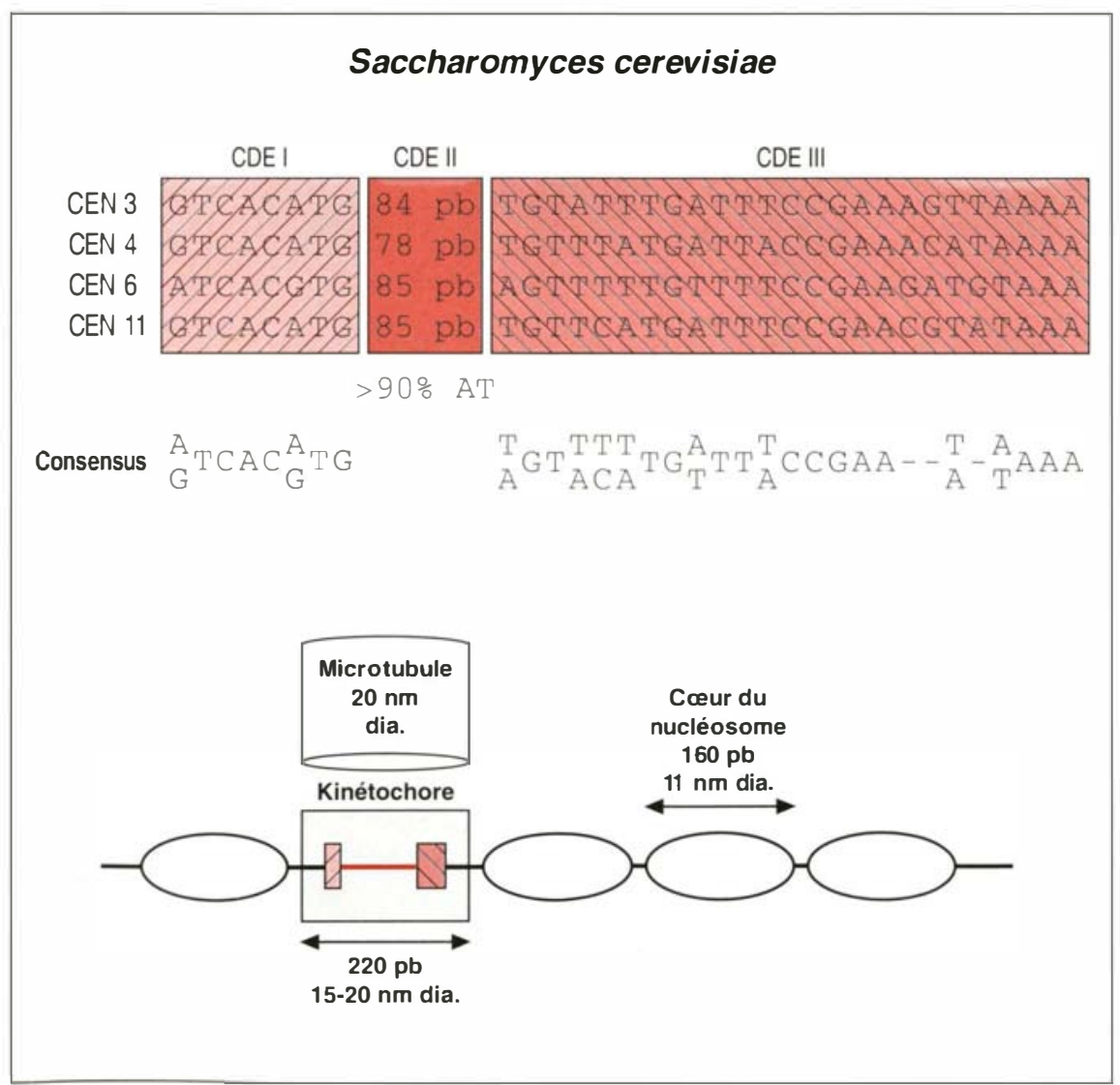

Figure 1. Structure de I'ADN centromérique de 4 chromosomes de $\mathrm{S}$. cerevisiae. Il comprend trois éléments CDE (centromere DNA elements) très homologues d'un chromosome à l'autre.

$\mathrm{m} / \mathrm{s} n^{\circ} 3$ vol. 110 , mars 94 chromosomes, et par conséquent les centromères, ne sont visibles ni che\%. les protozoaires, ni chez la levure, du fait de l'absence de condensation de la chromatine au cours de la prophase de la mitose. Au centromère s'ajoute une structure protéique distincte, mais essentielle, le kinétochore, auquel s'attachent les microtubules du fuseau mitotique. Ce dernier n'est visible, sous forme d'une structure trilamellaire, qu'au microscope électronique après marquage par des anticorps antikinétochore fluorescents. En fait, il est de plus en plus difficile de considérer le centromère et le kinétochore comme des entités distinctes - il vaut mieux parler d'un complexe centromère-kinétochore - les constituants moléculaires de chacune des deux structures étant largement imbriqués les uns dans les autres [3].

L'étude de la levure a permis, ces dernières amnées, de comprendre au

moins partiellement ce qui constitue un centromère au niveau moléculaire et comment il fonctionne. Mais les différences avec les mammifères sont très importantes, comme cela sera discuté par la suite.

Chez $S$. cerevisiae, la structure de la portion d'ADN qui assure la fonction centromérique est extrêmement simple et proche d'un chromosome a l'autre. On peut en caractériser une séquence consensus (figure 1), qui comprend trois éléments (.I)E (centromere I)NA elements), I, II et III [4]. La situation se complique déjà chez. S. pombe puisque ses trois chromosomes portent des séquences d'ADN centromériques plus complexes et différentes d'un chromosome à l'autre, bien que formées d'éléments d'ADN répétés, de même type mais arrangés de façon variable (figure 2) [5].

Leur simplicité, d'une part, et une approche génétique de la fonction centromérique, d'autre part, ont permis la caractérisation des séquences d'ADN centromérique chez. S. cerevisiae. Elles sont constituées par deux courtes régions d'ADN conservées (8pb pour (iDE I et 25 pl) pour C.DE III) séparées par (.I)E II (78 à $86 \mathrm{pb}>9() \% \mathrm{~A}+\mathrm{T})$. Par analyse de mutations in vitro, le rôle essentiel de certaines bases dans (IDE III a pu être établi. Elles permettent, en effet, une liaison spécifique avec (BBF3 (centromere binding factor 3), complexe de 240 kDa formé de trois polypeptides CBF A, B et C, dont le fonctionnement semble réglé par des phosphorylations. L'analyse de nombreuses délétions et insertions dans (.I)E II a montré que seule la richesse en $\mathrm{A}+\mathrm{T}$ de cet élément était nécessaire au bon fonctionnement du centromère de levure, sans que la séquence elle-même ait besoin d'être particulièrement stricte. Une délétion complète de C.DE I n'a qu'un effet réduit sur la fidélité de la ségrégation chromosomique. Par digestion à la nucléase, on a pu montrer que l'ADN centromérique de $S$. cerevisiae était engagé dans un complexe nucléoprotéique de 20) à 25() pb. Ces domnées sont bien plus complètes que che\% les mammifères, malgré l'impossibilité chez. la levure de visualiser les chromosomes, et malgré l'absence de kinétochores 


\section{RÉFÉRENCES}

1. Heimzel SS, Krysan Pi. Tan C:T (alos MP. Autonomous I)NA replication in human cells is affected by the size and the source of the I)NA. Mol (ell Biol 1991: II: $226.3-71$.

2. Farr (:, Fantes J, Goodfellow P, cooke H. Functional reintroduction of human telomeres into mammalian cells. Proc Nall Acad Sci LSA 1991; 88: 7006-10.

3. Brinkley BR, Ouspenski l, Zinkowski RP Structure and molecular organization of the centromere-kinetochore complex. Trends (iell Biol 1992: 2: 15-21.

4. Clarke L. Centromeres of budding and fission yeasts. Trends (ienel 199():6:150-4.

5. (Chikasige Y, Kinoshita N, Nakesoko Y' Matsumoto T, Mukarami S, Niwa (), Yanagida M. Composite motifs and repeat symetry in $S$. pombe centromeres: direct analysis by integration of Not 1 restriction sites. (iell 1989; 57: 739-51.

6. Trask BJ. Fluorescence in situ hybridiration: applications in cytogenetics and gene mapping. Trends (ienet 1991; 7 : $149-54$.

7. Marcais B, (iérard A, Bellis M, Roizès (;.Taq 1 reveals two independent alphoïd polvmorphisms on human chromosomes 13 and 21. Hum (ienet 1991: 86: $3(17-10$.

8. Marçais B, Bellis M, Gérard A, Pagès M Boublik Y, Roizès (;. Structural organization and polymorphism of the alpha satellite DNA sequences of chromosomes 13 and 21 as revealed by pulse field gel electrophoresis. Hum Genet 1991; 86: 311-6.

9. (harlieu JP, Iaurent AM, (arter D)A, Bellis M, Roizès (;. 3' Alu PC:R : a simple and rapid method to isolate human polymorphic markers. Nucleic Acids Res 1992 ; 2(): $13.33-7$.

10. Laurent AM, Marcais B, Muléris $M$ Roizès (;. A rapid and simple method to isolate and characterize highly polymorphic markers from the centromeric regions of the human chromosomes. Nucleir Acids Res 1994; (sous presse).

II. Carine K, Solus J, Waltyer E, Manch(itron J, Hamkalo BA, Scheffler IF. (hinese hamster cells with a minichromosome containing the centromeric region of human chromosome. Somatic (ell Mol (ienet $1986 ; 12: 479-91$.

12. Haaf T, Warburton PE, Willard $\mathrm{HF}$ Integration of human alpha-satellite I)NA in simian chromosomes: centromere pror tein binding and disruption of normal chromosome segregation. (ell 1992; 70) $681-96$.

13. Tyler-Smith (, Willard HF. Mammalian chromosome structure. (iur (Op) (iened Dev $1993 ; 3: 39()-7$.

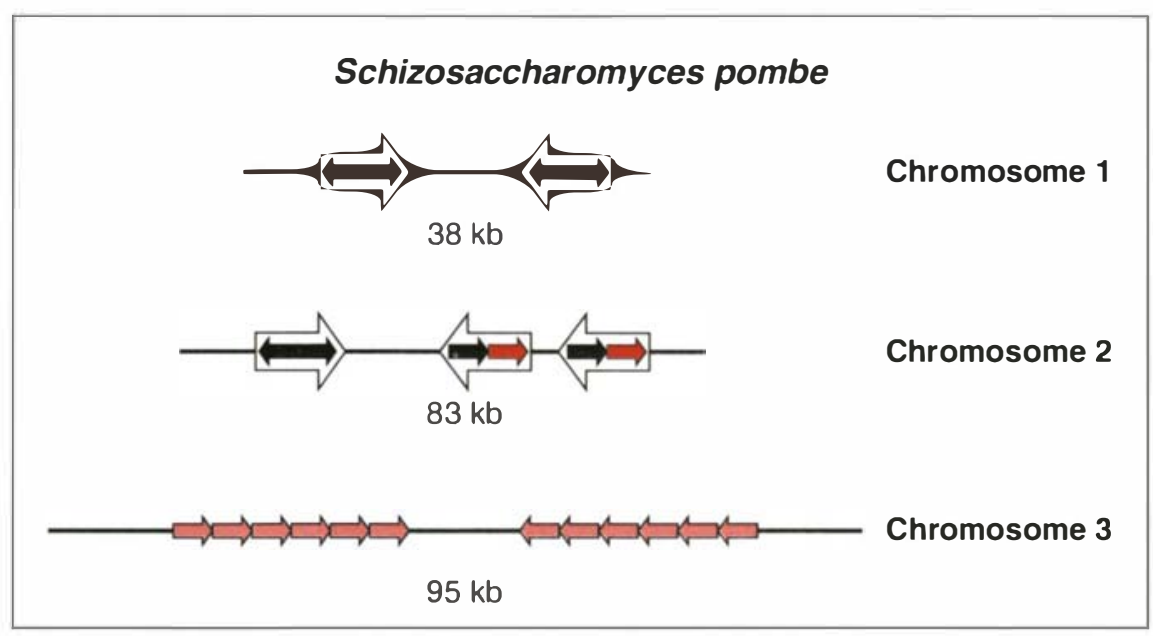

Figure 2. Structure de I'ADN centromérique des 3 chromosomes de S. pombe. Les flèches représentent différents types de séquences d'ADN répété. Les mêmes séquences sont retrouvées, en ordre et en nombre différents, dans les centromères des chromosomes 1 et 2. L'ADN centromérique du chromosome 3 a une séquence différente.

Tableau I

LES ADN SATELLITES CONNUS CHEZ L'HOMME

\begin{tabular}{|c|c|c|c|}
\hline Nom & $\begin{array}{c}\text { Taille unique } \\
\text { de répétition } \\
\text { (paires de bases) }\end{array}$ & Chromosomes & Références \\
\hline$\alpha$, alphoïde & 171 & Tous & {$[70-71]$} \\
\hline$\beta$ & 68 & $\begin{array}{c}1,9,13,14,15, \\
21,22 \text { et } Y\end{array}$ & $\begin{array}{l}{[72]} \\
{[73]} \\
{[74]}\end{array}$ \\
\hline Satellite 1 & 48 & $\begin{array}{c}21,22, Y, \\
\text { autres? }\end{array}$ & {$[75]$} \\
\hline Satellite 2 et 3 & 52 & $\begin{array}{c}\text { La plupart, } \\
\text { probablement } \\
\text { tous }\end{array}$ & {$[75-76]$} \\
\hline
\end{tabular}

Bien que la nomenclature concernant les $A D N$ satellites humains ait été plus ou moins formalisée [68], on trouve encore des appellations non contrôlées. On appelle ADN satellites "classiques" les ADN satellites I, II et III tels qu'ils étaient purifiés par centrifugation à l'équilibre dans des sels de césium [69]. La mise en évidence de leurs caractères hétérogènes en séquences les a fait dénommer ADN satellites 1, 2 et 3 . Cette nomenclature n'est, de toutes les manières, pas satisfaisante car il existe, pour chacun d'entre eux, y compris pour I'ADN alpha satellite, des sous-familles correspondant à des domaines distincts les uns des autres qui ont, le plus souvent, une homologie de séquence réduite. On peut s'en rendre compte notamment dans l'exemple des chromosomes 13, 14 et 21 qui est donné dans la figure 8. En fait, il serait souhaitable de désigner tout à fait autrement les ADN satellites pour mieux rendre compte de leur diversité, mais cela dépasse le cadre de ce texte. 
qui rend très difficile l'étude de l'assemblage du centromère au microtubule.

La situation est inverse che\% les mammifères che\% lesquels cette visualisation est relativement aisée. Mais l'absence de commaissances des éléments qui constituent centromères et kinćtochores, leur apparente complexité et une génétique encore difficile à développer font que l'on est bien loin de comnaître les centromères de mammifères comme ceux de $S$. cernisicie.

\section{Les ADN satellites, des constituants universels des régions centromériques}

A la différence de la levure, les séquences d'AI)N qui assurent la fonction centromérique chez les mammifères ne sont pas commues. Chez tous ces organismes, cependant, comme d'ailleurs chez les plantes, les insectes ou d'autres genres encore, les régions centromériques contiennent des quantités importantes de séquences répétées en tandem, les ADN satellites. I eur dénomination provient de la propriété qu'ils ont, souvent, de se rassembler sous la forme d'un pic satellite de densité particulière dans un gradient de sels de césium à l'équilibre. Mais leur propriété principale est ce caractère répété en tandem, exactement comme les minisatellites ou les microsatellites qui sont donc abusivement ainsi dénommés.

I)'une espèce à l'autre, ils sont extrêmement variables en quantité, nombre, séquence et taille d'unité de répétition. Ainsi, pour nous en tenir à cette seule comparaison, deux ADN satellites sont détectés che\% la souris; l'un, majeur, a une unité de répétition de 2.34 paires de bases et représente environ $7 \%$ de l'ensemble des séquences du génome murin; l'autre, mineur, a une unité de répétition de 120 paires de bases, représente une fraction de pourcentage du génome total et a une lointaine homologie de séquence avec le premier. Mais ni l'un ni l'autre n'ont aucune homologie de séquence avec aucun des AI)N satellites connus chez l'homme (Tableau I). I e plus abondant et le plus étudié de ces demiers est I:AI)N alpha satellite - on parle parfois de séquences alphoïdes - qui représente plusicurs pourcents du génome total humain. Il est consti-

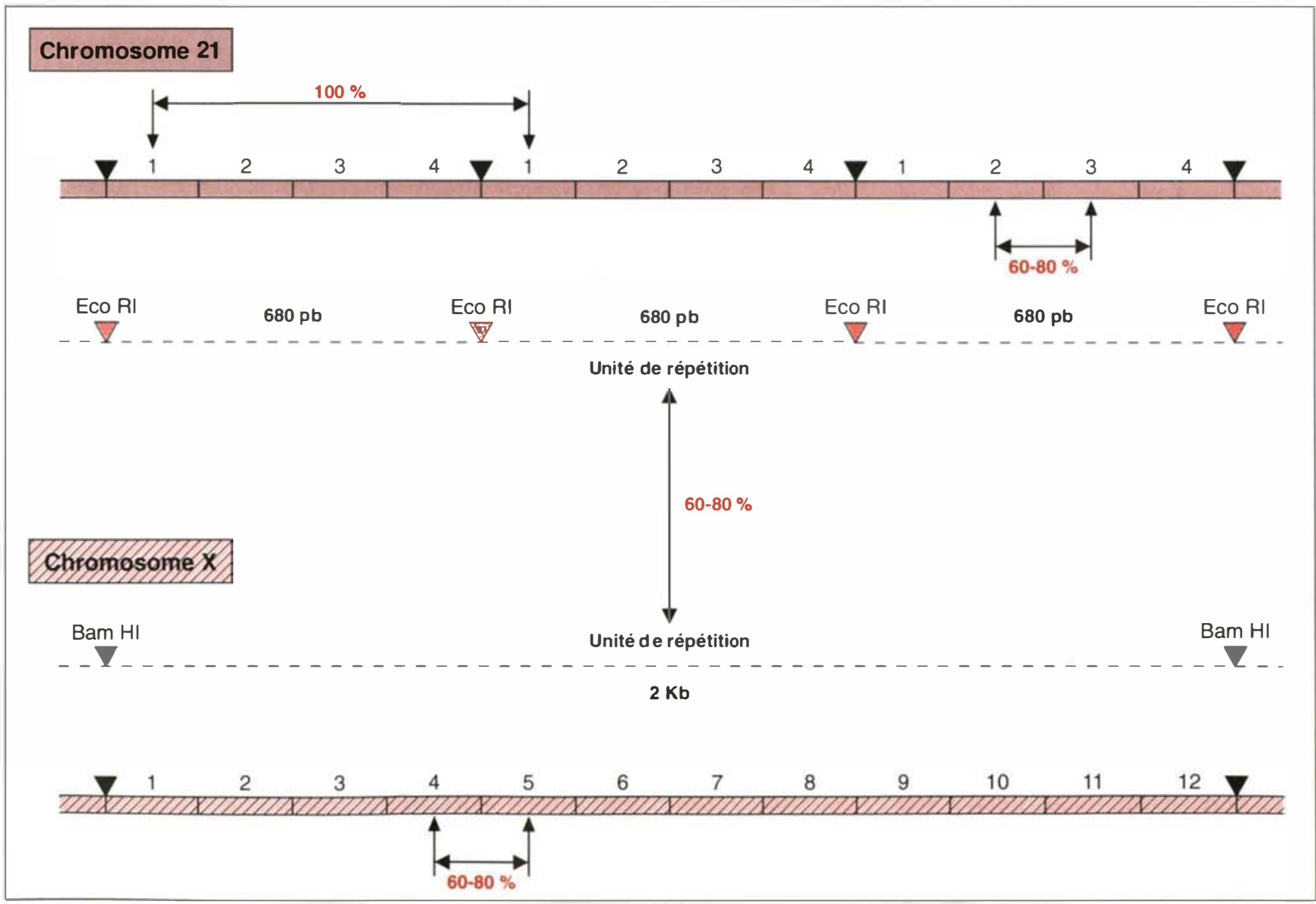

Figure 3. Organisation de I'ADN alpha satellite sur les chromosomes 21 et X. Les sites Eco RI et Bam HI définissent des unités de répétition de, respectivement, 4 et 12 monomères. L'identité de séquence entre unités de répétition est proche de $100 \%$ tandis que celle entre monomères d'une même unité de répétition ou entre unités de répétition de deux chromosomes différents varie entre $60 \%$ et $80 \%$. 


\section{RÉFÉRENCES}

14. Matsumoto H, Masukatla H. Muro Y Norati N, Okarati I. A human centror mere antigene ((:F.NP-B) interacts with a shere specilic se(puence in alphoïd D)NA, a human centromeric saltellite. / (iell Biol $1989 ; 109: 196.3-7.3$

15. Rattuer JB.The structure of the mammalian centromere. Bio lissons 1991: 13: ()) 1 (i).

16. Schlegel R, Paudoe AB. Calfeineinduced moncompling of mitosis fom the completion of DNA replication in mamma lian colls. Srience 1986; 232: 1264-6i.

17. Zinkowsti RP, Merne J, Brinkley BR. The centomere-kinetochome complex : a repeat subumit model. / Cell Biol log)l: $113: 1091-109$.

18. Saitoh H, Tomkicel J, conke C:A, Ratric H, Mature M, Rothlield NF, Eannshaw W(:. (.F.NP-C, an atut()antigen in sclerodermat, is a compenent of the human inner kinesochore plate. (ill 1992); 70 : $115-25$.

19. Suanss F, Varsharsky A. A protein binds to a satellite I)NA repeat at three specitic sites that would be brought inte mutual proximity by I)NAt folding in the mucleosome. (ell 1984: 37: 889-9(0)1

2(). (irady I)L, Ratliff RI, Robinson I)I. Mc aunlies F(:, Meyne J, Mloyris RK. Highly conserved repetitive DNA sequences are present at human centromeres. Proc Vall

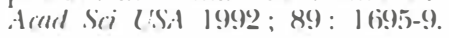

21. Peterson JB, Ris H. Flectron microscopic study of the spindle and chromosome movement in the veast Sacharommes cerentisiofe. I Cell Sci 1976; 24: 219-42.

22. Cocper KF, Richard BF, Tyler-Smith C: Suructure of the sequences adjacent on the centromeric alphoid DNA araty on the human chromosome Y. / Mol Biol l(9)3; 23()$: 787-99$

23. Wevick R, Willard HF. Physical map) of the centomeric region of human chromosome 7 : relationship between two distinct alphat sattellite arays. Vurleic Acids Res 1991 ; 19: $2(9) 5-3(1) 1$

24. Jackson MS, ef al. Characterization of a boundaty between satellite III and alphoid sepiuences in human chromosome 1(). Nucleir Aciols Res 19(9); 20: 4781-7.

25. (hoo KH. Role of acrocentric cen-pter I)NA in Robertsonian Iranslocation and chromosomal nom-disjunction. Mol Biol Mart $19(9): 7: 4.37-49$. tué de répétitions de 171 paires de bases (monomères), organisées en tandem, et il est présent sur tous les chromosomes humains dans leurs régions centromériques. (haque chromosome est équipé d'une sousfamille spécifique du même ADN alpha satellite qui se distingue des autres par deux caractères particuliers: (1) les monomères sont organisés en unités d’ordre supérieur comprenant un nombre variable de monomères selon les chromosomes. Ainsi, sur le chromosome 21, l'enzyme EcoRI libère une unité de 680 paires de bases (4 monomères) alors que Bamhll en libère une de 2 kilobases environ (12 monomères) sur le chromosome X (fighre 3); (2) si l'identité de séquence d'une unité à l'autre sur chaque chromosome est proche de $100 \%$, il n'en va pas de même d'un monomère à l'autre d'une même unité (figure 3) et, surtout, d'une unité à l'autre sur deux chromosomes différents, l'identité de séquence étant, alors, réduite de (6) \% à $80 \%$ selon les cas.

Ciette homologie réduite de séquence peut être exploitée en génétique moléculaire ou en cytogénétique par hybridation in silu. Il est facile, en effet, en utilisant des conditions d'hybridation appropriées, de distinguer les séquences alpha satellites centromériques d'un chromosome à l'autre, ce qui est de plus en plus utilisé pour l'analvse cytogénétique dans diverses situations (figure 4) [6].

La différence de séquence des ADN alpha satellites d'un chromosome a l'autre souffre, cependant, quelques exceptions. l.es chromosomes acrocentriques* $(13,14,15,21$ et 22) portent, en effet, des ADN alpha satellites qui ont plus d'homologie de séquence entre eux qu'avec les autres chromosomes, au point que les chromosomes 13 et 21 sont indistinguables par ce critère (figure 5) (leurs ADN alpha satellites ont, en effet, 99,7\% d'identité). I.es chromosomes acrocentriques sont porteurs des gènes des $A R N$ ribosomiques et on pense que la situation décrite ci-dessus est le résultat de

* Chromosome acrocentrique : domt le centromère est localisé très près d'une des extremmités. mécanismes d'homogénéisation interchromosomique due précisément à la présence de ces gènes. I.es autres chromosomes n'ayant pas les mêmes contraintes dues aux gènes ribosomiques (l'organisateur nucléolaire* les fait échanger de l’information plus fréquemment) sont libres d'évoluer indépendamment les uns des autres.

La question de savoir comment ces structures sont engendrées est loin d'être résolue, le modèle consensuel, (auquel nous n'adhérons pas [7]), faisant intervenir une accumulation de crossing-over inégaux.

\section{Les ADN satellites représentent les fractions les plus polymorphes du génome}

Ce que nous venons de décrire pourrait laisser croire que nous sommes plongés dans un océan d'uniformité et qu'il serait extrêmement difficile d'en tirer des enseignements utiles du point de vue génétique. En fait, les $\mathrm{ADN}$ satellites représentent probablement les régions les plus polymorphes des organismes supérieurs. Ce polymorphisme se "mesure" par l’hétérozygotie, ou le pourcentage d'hétéromygotes à un locus domné que l'on trouve dans les populations. Celui-ci est fonction du nombre d'allèles que l'on rencontre. L.hétérozvgotie des microsatellites est élevée, puisqu'elle atteint souvent 7 () \% et plus. L'ADN alpha satellite, lui, offre une hétérozygotie de près de 10()$\%$. En effet, si l'on hydrolvse l'ADN génomique par des enzymes de restriction dont le site est absent de l’unité de répétition spécifique d'un chromosome, on va libérer les séquences d'ADN alpha satellite sous la forme d'un seul fragment d'AION contenant l'ensemble des unités de répétition de ce bloc. La taille de ce bloc est mesurable par électrophorèse en champ pulsé. C'est ce que nous avons réalisé pour l'ADN alpha satellite des chromosomes 13 et 21 [8] (figure 5). Plusieurs dizaines d'individus non apparentés ont été ainsi analysés. Tous offrent des profils de restriction différents les uns

\footnotetext{
* Organisateur mudeolaire: structure du muclécole au niverui de laquelle les gèmes rilossomiques des différents chromosomes somt trunsorits.
} 


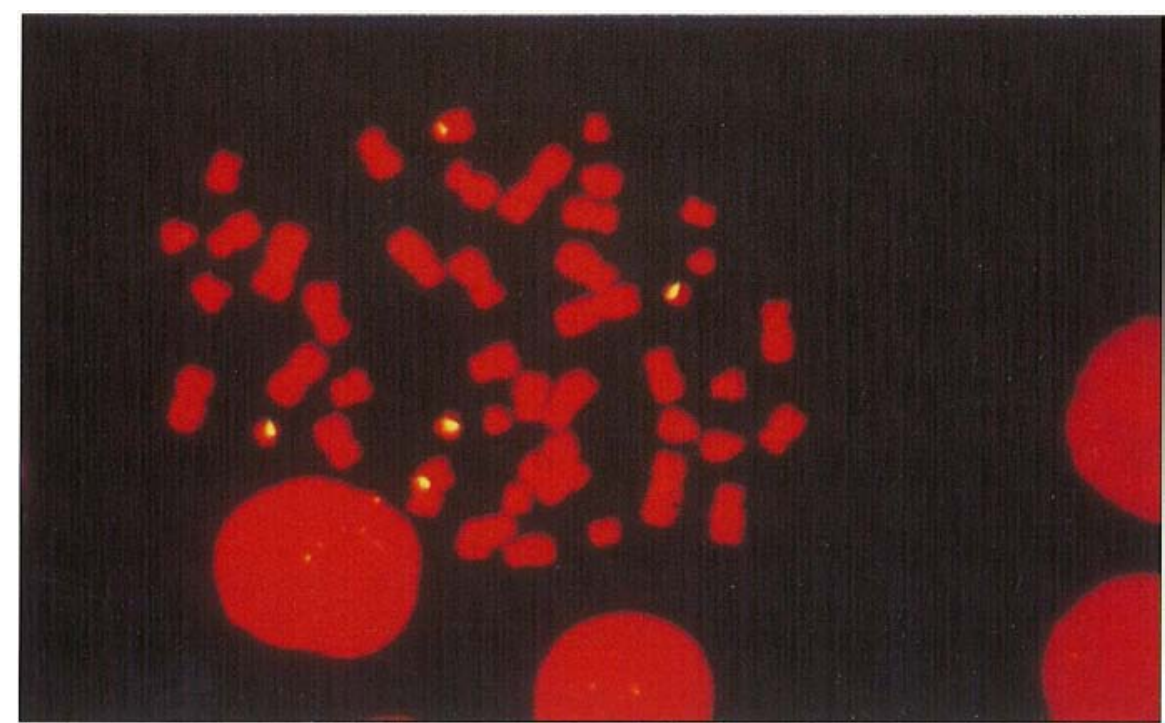

Figure 4. Hybridation in situ des cellules en métaphase d'un individu trisomique effectuée au laboratoire avec une sonde $d^{\prime} A D N$ satellite alpha, spécifique des chromosomes 13 et 21. La sonde utilisée (isolée par Y. Yurov, Moscoul est constituée d'un cosmide contenant de l'ADN satellite alpha du chromosome 21. On distingue un certain hétéromorphisme (intensité variable du signal) qui permet, dans ce cas, de déterminer l'origine parentale de la non-disjonction méiotique ayant conduit à la trisomie 21.

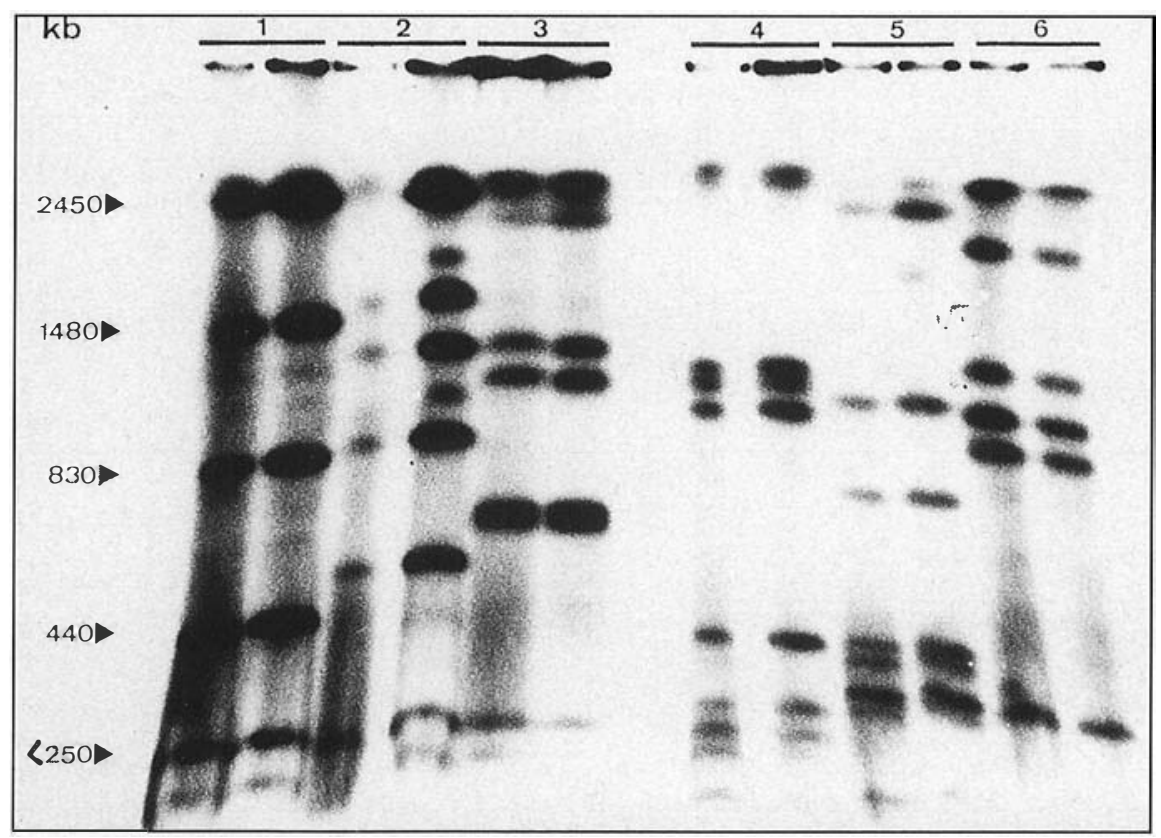

Figure 5. Analyse, par électrophorèse en champ pulsé, de la taille des blocs d'ADN alpha satellite présents sur les chromosomes 13 et 21 de six individus non apparentés après coupure de leur ADN génomique total par BamHI. Tous offrent des profils de restriction différents les uns des autres. (Reproduit de [8]). des autres: il est assez rare qu'une seule bande d'ADN soit partagée par deux ou plusieurs individus. Nous avons pu estimer précisément la taille de ces blocs dans 7 chromosomes 21: elle varie de 420 kilobases pour le plus petit à 5,6 mégabases pour le plus grand, soit d'un facteur 14 , avec tous les intermédiaires possibles. Il s'agit donc de séquences du même type que les mini- ou microsatellites (nombre variable de répétitions en tandem ou VNTR en anglais), mais dont les variations d'un individu à l'autre sont encore plus considérables.

A cette variabilité de tailles de bloc s'ajoute une variabilité de séquences qui a pour origine deux phénomènes indépendants: (1) d'abord, comme toute autre séquence d'ADN du génome, les séquences alpha satellites sont susceptibles de variations nucléotidiques dues à des mutations. Ce phénomène est d'autant plus important qu'aucune pression de sélection ne s'exerce sur la séquence même des ADN satellites; (2) de plus, des phénomènes d'amplifications locales se produisent fréquemment. En témoignent les polymorphismes de longueurs de fragments de restriction que l'on peut mettre en évidence comme, par exemple, avec l'enzyme de restriction TaqI [7] (figure 6). Ainsi les blocs d'ADN alpha satellite sont-ils formés de différents domaines adjacents les uns aux autres qui ajoutent à la diversité de ces séquences.

Bien que non mise en évidence aussi nettement que dans le cas de l'ADN alpha satellite humain, une variabilité de même tvpe existe certainement pour tous les ADN satellites chez tous les organismes où on les rencontre.

Ce polymorphisme n'a malheureusement pas pu être mis en valeur comme on le souhaiterait pour des analy'ses de liaison entre centromères ét locus proximaux. Cela est dû à la difficulté de mettre en ceuvre en routine la technique d'électrophorèse en champ pulsé et/ou au caractère bi-allélique seulement des polymorphismes de restriction décrits ci-dessus et à leurs fréquences parfois faibles (par exemple, le polymorphisme TaqI sur le chromosome 21 n'est présent que dans une 


\section{RÉFÉRENCES}

26. Trowell HE, Nagy A, Vissel B, Choo KHA. Long-range analyses of the centromeric regions of human chromosomes 13,14 and 21 : identification of a narrow domain containing two key centromeric DNA elements. Hum Mol Genet 1993; 2: 1639-49.

27. Wevrick R, Willard VP, Willard HF. Structure of DNA near long tandem arrays of alpha satellite DNA at the centromere of chromosome 7. Genomics 1992; 14: 912-23.

28. Johnson DH, Kroisel PM, Klapper HJ, Rosenkranz W. Microdissection of a human marker chromosome reveals its origin and a new family of centromeric repetitive DNA. Hum Mol Cienet 1992; 1: 741-7.

29. Tyler-Smith C, Oakey RJ, Larin Z, Fisher RB, Crocker M, Affara NA, FergusonSmith M, Muenke M, Zuffardi O, Jobling MA. Localisation of the DNA sequences required for human centromere function through an analysis of rearranged $\mathrm{Y}$ chromosomes. Nature Genet 1993; 5: 368-75.

30. Rovira C, Beermann W, Edstrōm JE. A repetitive sequence associated with the centromeres of Chironomus pallidivittatus. Nucleic Acids Res 1993; 21 : 1775-81.

31. (jartler SM, Riggs AD. Mammalian Xchromosome inactivation. Annu Rev (jenet $1983 ; 17: 155-9()$.

32. Cattanach BM. Position-effect variegation in the mouse. Genet Res 1974; 23 291-306.

33. Muller HJ. Types of viable variations induced by X-rays in Irosophila. J Genet 1930 ; 22 : 299-334.

34. Spofford JB. Position-effect variegation in Drosophila. In Asburner M., ed.: The genetics and biology of Drosophila London Academic Press. 1976: vol. 1c: 955-1018.

35. Grigliatti T. Position-effect variegation. An assay for non histone chromosomal proteins and chromatin assembly and modifying factors. In: Methods in cell biology. San Diego, Academic Press : 1991 ; vol 35: $587-627$.

36. Cilark RF, Elgin SC:R. Heterochromatin protein l, a known suppressor of position-effect variegation, is highly conserved in Drosophila. Nucleic Acids Res 1992; 20 : 6067-74

37. Singh PB, Miller JR, Pearce J, Kothary R, Burton RD, Paro R, James TC, Gaun SJ. A sequence motif found in a Irosophila heterochromatin protein is conserved in animals and plants. Nucleic Acids Res 1991; 19: 789-94.

38. Eberl DF, Duyf B, Hilliker AJ. The role of heterochromatin in the expression of a heterochromatic gene, the rolled locus of Drosophila melanogaster. Cienetics 1993; 134 : 277-92.

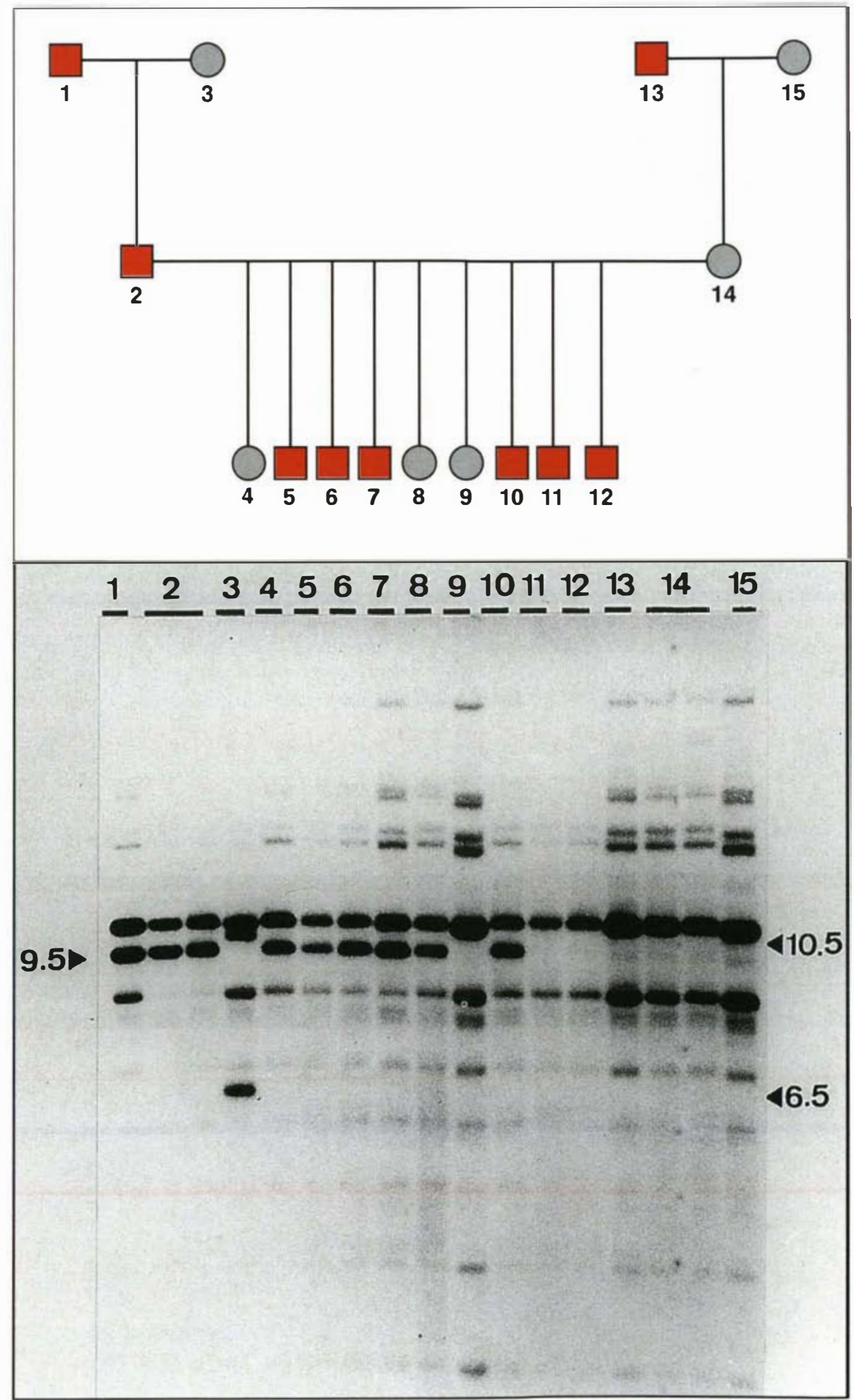

Figure 6. Polymorphismes de longueurs de fragments de restriction obtenus dans une famille du CEPH (Centre d'étude du polymorphisme humain) dans les séquences alpha satellite des chromosomes 13 et 21 après coupure par Taql. Sur le chromosome 21, le polymorphisme correspond à la bande 9.5 fois le monomère. Sur le chromosome 13, il est représenté par la présence simultanée des bandes 10.5 et 6.5 fois le monomère. Ces polymorphismes sont dus à des phénomènes d'amplifications locales. (Reproduit de [7].) 
seule famille du CEPH - Centre d'étude du polymorphisme humain - sur 40 testées).

Il a donc fallu chercher d'autres types de polymorphisme dans les régions centromériques pour pallier cette carence pratique. Ces polymorphismes existent bel et bien aux extrémités des séquences de types Alu et LlHs qui ont transposé dans les régions centromériques. Une méthodologie a été développée pour les mettre en évidence et les caractériser $[9,10]$.

\section{Les ADN satellites constituent-ils les séquences centromériques des mammifères?}

Sans qu'il ait été possible, jusqu'à présent, de caractériser de façon décisive les ADN satellites comme responsables de la fonction centromérique, un certain nombre d'arguments font penser, cependant, qu'ils pourraient au moins contribuer à cette fonction. D'abord, l'universalité de la présence des ADN satellites dans les régions centromériques des chromosomes est frappante et, si leurs séquences et leurs quantités sont extrêmement variables d'une espèce à l'autre et d'un individu à l'autre, rien n'empêche de penser que quelques copies seulement pourraient suffire. Il n'a jamais été noté d'absence totale de séquences alpha satellite au centromère d'un seul chromosome humain, alors que les exemples abondent où une délétion des autres ADN satellites humains s'est produite ou, encore, où l'un d'entre eux est carrément absent (c'est le cas, par exemple, de l'ADN bêta satellite qui n'est détectable que sur les chromosomes 1,9 , les 5 acrocentriques et $Y$ ). Ajoutons que dans les quelques cas où un minichromosome dans des cellules humaines a été détecté, celui-ci comportait toujours une certaine quantité d'ADN alpha satellite en son centromère [11]. Il faut cependant noter que la détection des séquences satellites centromériques n'a jamais été recherchée au niveau d'une ou de quelques copies. La participation des autres ADN satellites à la fonction centromérique reste donc une question ouverte.

Récemment, par transfection d'ADN alpha satellite humain dans des cellules $\operatorname{COS} 7$ de singe vert d'Afrique en culture, on a pu montrer que la seule présence d'ADN alpha satellite entraînait la liaison d'une ou de plusieurs des protéines centromériques CENP, dont probablement CENP-B, et, surtout, que l'ADN alpha satellite ainsi introduit perturbait la ségrégation normale des chromosomes [12]. Il apparaît, d'après ces expériences, qu'une quantité suffisante d'ADN alpha satellite serait donc capable de contribuer au fonctionnement centromérique dans un ou plusieurs de ses aspects. Encore plus récemment, Tyler-Smith et al. [13] ont étudié la structure comparée de centromères inactifs et actifs dans le chromosome Y. Ils ont pu montrer par une étude structurale fine qu'un bloc d'ADN satellite alpha, associé à environ 300 kilobases de séquences non satellites de Yp, était toujours présent dans les centromères actifs, contrairement aux centromères inactivés par réarrangements moléculaires (voir paragraphe suivant et figure 7).

Nous avons vu qu'à un centromère est toujours associé un kinétochore auquel viennent s'attacher les microtubules du fuseau mitotique. Il est donc probable que les séquences d'ADN assurant la fonction centromérique se trouveront associées au kinétochore. ('’est le cas précisément de l'ADN alpha satellite dont on a montré la liaison à (.ENP-B, une des protéines du complexe centromère-kinétochore [14] (Tableau II) par l'intermédiaire d'une séquence de 17 nucléotides seulement (appelée boîte (ENP-B) que l'on retrouve, fait troublant, dans l'ADN sattellite de la souris avec une homologie significative [15]. (On a déjà une bonne idée de la manière dont (ENP-B et les séquences d'ADN satellite sont associées. Dans des cellules mitotiques (CHO)

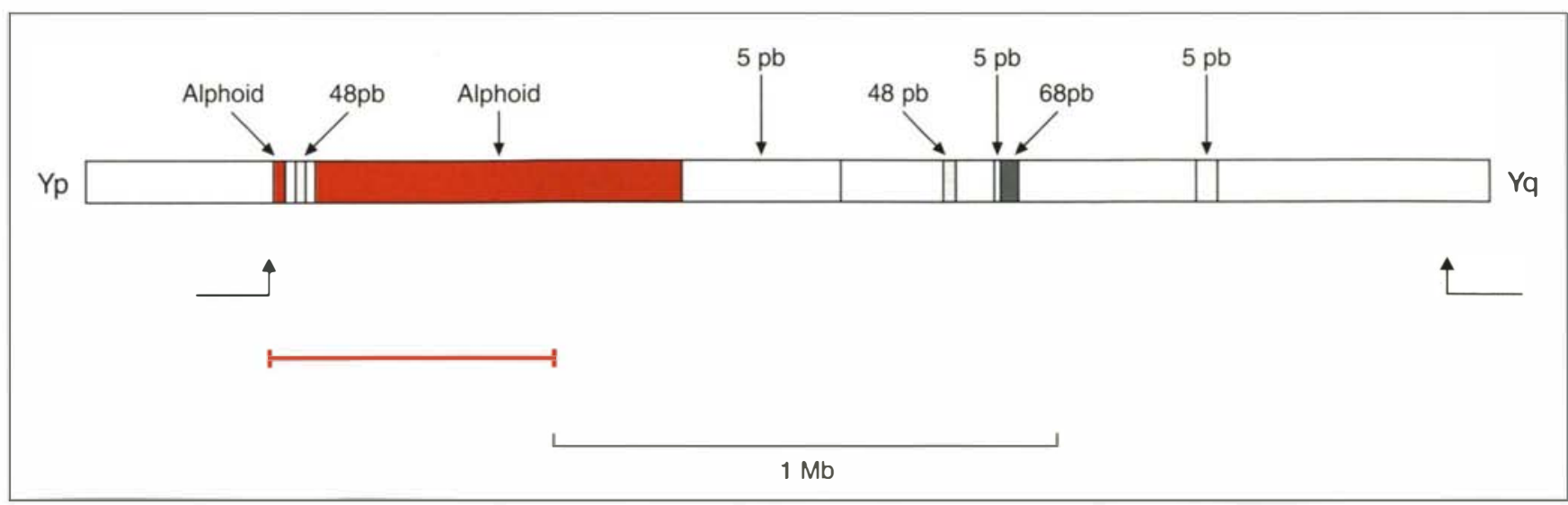

Figure 7. Carte physique de la région centromérique du chromosome $\boldsymbol{Y}$. Les différents ADN satellites présents dans la région sont indiqués (voir Tableau I). Les flèches sous la carte montrent les limites des séquences spécifiques des bras court $(Y p)$ et long $(Y q)$ du chromosome. Le trait rouge sous la carte indique la région minimum nécessaire au fonctionnement du centromère au cours des mitoses dans les hybrides somatiques où ils ont été analysés. (Reproduit d'après [13].) 


\section{RÉFÉRENCES}

39. Watwijk (, Flavell RA. Msp) 1, an isor schizomer of Hpa II, which cleaves both methrlated and ummethrlated Hpat II sites. Nucleir Acirls Res 1978; 5: 3231-6.

40. Wigler M, 1.ery D, Perucho M. The somatic replication of DNA methylation. (ifll 1981: 24: 33-40.

41. Pagès M, Roizès (i. Tïssue specificity and organisation of the (p) ; methvlation in calf saltellite DNA I. Nurleir Arids Res $1982: 10: 565-76$

42. Cooke HJ, Schmideke J. Cosclen JR. characterization of a human Y' chromosome repeated sequence and related sequences in higher primates. (Chromosomu $1982 ; 87: 491-502$.

43. Santord J, Fonester I, Chapman V, Chandley A, Hastie N. Methylation pattems of repetitive DNA sequences in germ cells of Mus musculus. Nucleir Acids Res 1984; 12: $28233-36$.

44. Mitchell AR. Hypomethylation of human heterochromatin detected by restriction enzome nick translation. Lixy ciell Res 1992; : $2(1) 2$ : 203-6.

45. Almeida A, Kokalj-V'okac N, Lediançois 1), Viegas-P'équignot $\mathrm{E}$, Jeampierre $\mathrm{M}$, Dutrillaux B, Malfor B. Hrpomethrition of classical satcellite $\mathrm{DN}_{\mathrm{S}} \mathrm{A}$ and chromosome instability in lvmphoblastoid cell lines. Hum (ientet 1993: 9) : 538-46.

46. Jeanpierre M, Turlean (:, Aurias A, Pricur M, Ledeist F, Fïscher A, ViegasP'equignot F. An embromic-like methyla(iom pattem of classical satcellite DNA is observed in IC:F svindrome. Hum Mol (iemel $1993 ; 2: 731-5$.

47. Barlow DP. Methylation and imprinting: firom host defense to gene regulation? : Sriense 1993: 260): 3(0)9-10.

48. Reuter (;, Spierer P. Position Fffect Variegation and chromatin proteins. Bio tissays 1992; 9: (605-12.

49. (iravholi (:H, Friedrich U, (ap)rani M, Jorgensen $\mathrm{AL}$. Breakpoints in Robertsonian translocations are localized to satcellite III D) $\mathrm{N}_{\mathrm{A}}$ by fluorescence in silu hobridization. (ipnomics 1992; 14: (924-30.

50. Vig BK. Sequence of centromere separation: a possible role for repetitive IDNA. Mulagenesis $1987 ; 2$ : 15.5-9.

51. Fitzgerald PH. A mechanism of $x$ chromosome anceuploidy in lvmphocites of ageing women. Humbingentik 1975; 28: $15.3-8$.

52. Roizès (; Marçais B, Bellis M, (haulieu JP. The origin of non-disjunction in human chromosomes: an hopothesis. life Sici Adv 19992; I1: 239)-40)

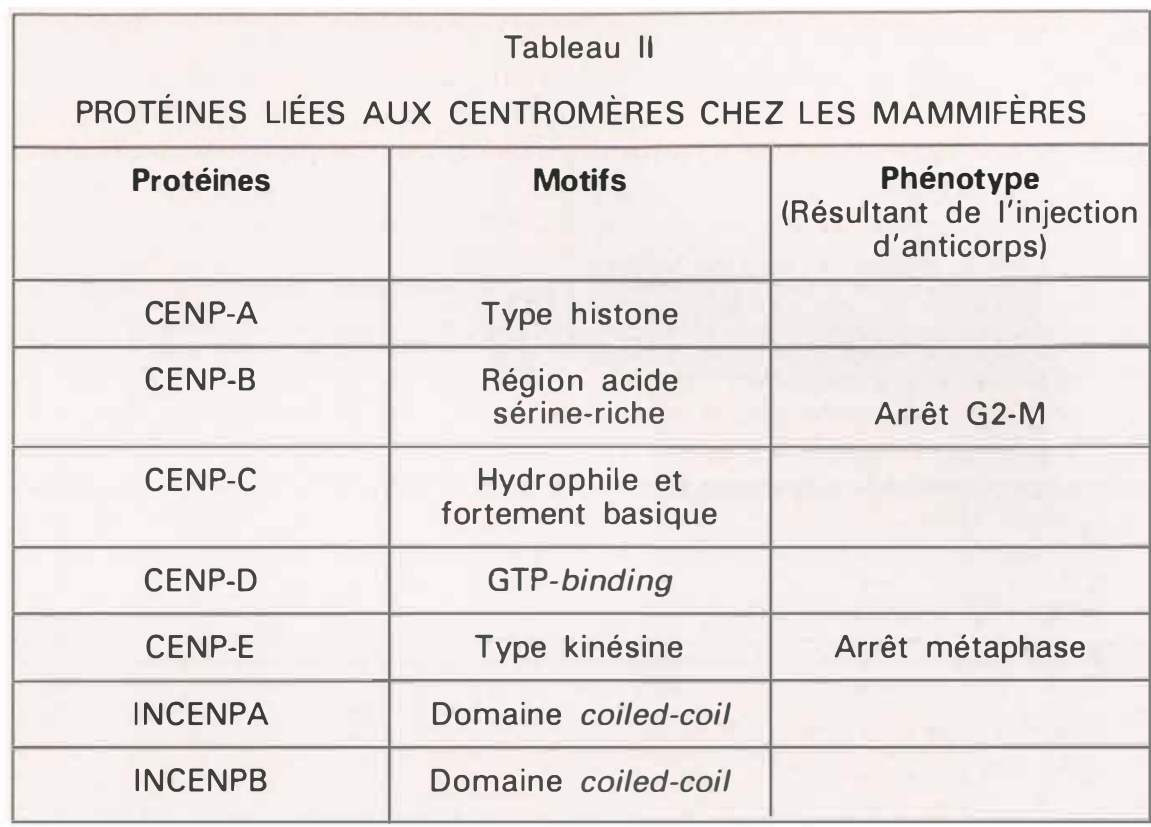

CENP: centromeric protein, INCENP: inner centromeric protein. (D'après [77].)

et Muntjak), où la réplication du génome est inhibéc par In traitement à l'hydroxvuréce (il s'agit de cellules dites ML'(is, mikolic cells with unreplicaled genomes), on a pu montrer, en effèt, que les kinétochores étaicunt formés de plusieurs segments capables de se lier aux microtubules [16]. ()n a pu, par ailleurs, après étirement (dix à vingt fois) des chromosomes de la métaphase sur lame par un léger traitement hypotonique, faire un marquage immunofluorescent avec des anticorps C.REST* et, sur les mêmes étalements, une hybridation in silu avec une sonde alpha satellite. L'existence de sous-mintés contenant les antigènes ('REST organisées en alternance avec des portions d'ADN satellite alpha dépourvues de tels antigènes a pu ainsi être confirmée $[3,17]$.

On suppose également que C.FNP(i est une protéine qui interagit avec l'AI)N [18]. On peut noter, enfin, qu'une protéine de type HMG; (high mobility group proteins, protéines non

\footnotetext{
* Ies patients presentamt le symolrome de C:REST (calcinosis, Raynand phenomemom, esephatgeal dismotility, scleroxlactyly, telangiectasiat) protuiseml des anticonges contre des anligimes spécifiques des kinélochores.
}

histones du noyau) peut également interagir fortement et spécifiquement in vitro avec l'AloN alpha satellite [19].

Ià encore, cependant, la structure intime de l'ensemble ADN-protéines qui assure la fonction centromérique est loin d'avoir été élucidéc. Fin particulier, la localisation de chacum des composants commus n'est pas encore déterminée avec certitude.

Les interactions avec des protéines ne sont cependant pas limitées à l'ADN alpha satellite puisqu'il a été montré que les ADN satellites II et IIl lient spéciliquement une protéine [2()]. ('hez la levure, l'ADN centromérique semble être directement lié au microtubule (il n'y en a qu'un par centromère) sans passer par une structure distincte comme le kinétochore des mammifères [21]. L'n débat est ouvert pour savoir si la couche externe des kinétochores de mammifères contiendrait les protéines équivalentes à celles qui assurent, chez la levure, la liaison avec les microtubules.

Il paraît difficile de trancher ce débat par simple comparaison entre la levure et les mammifères car, comme on le voit, la situation est considérablement plus complexe chez l'homme et il est tout à fait 
Chr 21 : bras p...sat3...pTRA1...pTRA4 ...pTRA2 ...sat3* ...pTRA7 ...alpha RI680...sat1...bras q

Chr 13 : bras p...sał3...pTRA1 ...pTRA4 ...pTRA2...sat3*...pTRA7 ...alpha RI680...bras q

Chr 14 : bras p...pTRS63...pTRS47 ...pTRA1...pTRA4 ...pTRA2 ...sat3*...pTRA7 ...alpha XT ...bras $q$

Figure 8. Ordre des différents domaines d'ADN satellites détectés dans les régions centromériques des chromosomes 21,13 et 14 depuis le bras court (p) jusqu'au bras long (q). Les différents domaines $d^{\prime} A D N$ alpha satellite sont: pTRA1, 4, 2 et 7 qui sont communs aux trois chromosomes, alphaRI680 (chromosomes 21 et 13) et pTRS63, 47 et alphaXT (chromosome 14). Deux domaines du satellite 3 sont également présents: sat 3 (chromosomes 21 et 13) et sat3* (21, 13 et 14). A noter, enfin, la présence d'un domaine sat1 sur le chromosome 21. Les différents domaines d'un même $A D N$ satellite n'ont qu'une homologie de séquence réduite entre eux et sont certainement polymorphes en taille d'un individu à l'autre. Les pointillés indiquent des distances variables (de quelques dizaines à quelques centaines de kilobases) contenant des séquences d'ADN totalement inconnues [26].

possible qu'un saut dans l'évolution se soit produit pour répondre à d'autres exigences de la reproduction che\% les organismes supérieurs. Nous ne nous engagerons donc pas trop en disant que l'ADN alpha satellite pourrait participer à la fonction centromérique, sans que ce soit a l'exclusion des autres ADN satellites ou d'autres types de séquences d'ADN, en permettant d'établir, par exemple, une structure compacte particulière aux régions centromériques des chromosomes.

\section{Anatomie d'une région centromérique humaine}

Nous l'avons déjà dit, les régions centromériques des chromosomes humains ne sont que partiellement explorées. On ne connaît pas en détail la manière dont les différents ADN satellites présents dans ces régions sont agencés les uns par rapport aux autres. Une certitude, cependant, ils sont organisés séparément sans que l'ordre dans lequel on les trouve soit une constante d'un chromosome à l'autre ni que la nature de leurs jonctions soit commue.

La mieux étudiée des régions centromériques est celle du chromo-

à la quasi-uniformité structurale des régions télomériques des mêmes chromosomes. Par exemple, sur le chromosome 7 , on trouve deux larges blocs d'ADN alpha satellite séparés sur près d'une mégabase par d'autres séquences [23], alors que sur le chromosome 10, les ADN satellites III et alpha sont adjacents [24].

L'agencement des différents blocs d'ADN satellites sur les chromosomes acrocentriques est encore différent, les gènes ribosomiques étant noyés au milieu de cet ensemble. On peut noter, en outre, la présence de deux familles de répétitions, les familles « 724 " et 7D), sur chacun d'entre eux et sur trois autres chromosomes [25]. Récemment, les ADN satellites des régions centromériques des chromosomes 13, 14 et 21 ont été analysés en détail [26]. U'ne carte physique et la caractérisation de différents domaines satellites particuliers sont ainsi disponibles pour chacun d'entre eux (figure 8). Les trois chromosomes se ressemblent très fortement, mais présentent, cependant, des différences significatives. Si l'on ajoute le polymorphisme de taille de blocs qui n'est pas pris en compte dans cette étude, on voit bien que la structure de ces régions est extrêmement complexe et variable non seulement d'un chromosome à l'autre, mais également entre chromosomes homologues eux-mêmes.

Les différents ADN satellites humains (Tableau I) sont présents de façon non uniforme dans les centromères des chromosomes humains, mais, en outre, leur arrangement est variable d'un chromosome à l'autre. Enfin, il ne faut pas oublier une série d'autres séquences répétées qui s'ajoutent au fur et à mesure de leur découverte et qui ont la même variabilité de distribution selon les chromosomes. Citons les séquences dites ATRS (AT-rich sequences) [27] et Sn5 [28]. Ces données sont résumées dans une revue récente [29]. La comparaison des séquences est certainement un bon guide pour rechercher des fonctions potentielles. Mais il est clair que tant que l'on ne disposera pas d'un test fonctionnel (les chromosomes artificiels de mammiferes le permettront-ils?), 


\section{RÉFÉRENCES}

53. Charlieu JP, Marçais B, Laurent AM, Roizes (i. New tools for the study of chromosome segregation and anemploïdy at the molecular level. In: V'ig BI). chromosome segregation and amentploidy. NATO Asi Series, vol. H 72. Berlin Heidelberg: Springerv'erlag, l)93.

54. Muleris M, Salmon JR, Duurilaux B. Cytogenetics of colorectal adenocarcinomas. Cancer (ienel Cjlogemel log)(); 46 : $14.3-56$

5.). Vig BK. The centromere-kinesochore complex in cancer. Cincer / 1993: 6: 24.3-5.)

56. Eamshaw WC: Ratuie BE, Mulligan RC: Visualization of centromere proteins (iENP$B$ and ('ENP-C: on a stable dicentric chror mosome in cytologrical spreads. (Chromosome $1989 ; 98: 1-12$

57. Lejeume J, I)utillaux $\mathrm{B}$, Rhéthoré $\mathrm{MO}$, Prieur .M. (omparaison de la structure fine des chromatides d'Homo sapiens el de Pan Iroglo. C:hromosoma 197.3; 43: 423-44.

58. Ijolo JW, Baldini A, Ward I)(;, Reeders SI, Wells R.A. ()rigin of human chromosome 2) an ancestral telomere-telomere fusiom. Proc Natl Acad Sri CSA 199) ; 88 : ()( )

59. Moroi Y, Peebles (;, Feitzler M], Stergerwald J, Ian M. Autoantibodv w centromere (kineochore) in sclerodema sera. Proc Nall Acad Sri l'St 1980); 77 : 1627-31.

(i). Radic MZ, I.undgren K, Hamkalo $B$. (iunature of mouse sattellite I)NA and comdensation of heterochomatin. Ciell l987; 5()$: 11() 1-8$

61. Carrea P', Martinez-Balbas MA, Portugal J. Azorin F. Identification of sequence elements (ontributing to the intrinsic curvature of the mouse satellite DNA. Nucleir Arids Res 1991: 19): 5(339)-44.

(i2. Martinez-Balbas A, Rodriguez-(ampos A, (iarcia-Ramirez M, Sainz J, Carrera I, Aymami J, Azorin F. Satellite I)NAs comtain sequences that induce curvature. Biochemis(ny 199(); 29): 2342-8.

(i3. Paseror) P, Sjakste N, Bletly C:, (iol C:, Marilley M. I.ong-range organization and sequence-directed cumature of Xenopus late vis salellile I 1)NA Nucleic Acids Res 1993: 21 : $47(03-10$.

64. Niedenthal Rh, Sen-(iupta M, Wilmen A, Hegemamn JH. (ipfl protein induced bending of yeast centromere I)NA element 1. Nucleic Acids Res 19993; 21: 472ti-3.3.

(i.). Karsenti F. V'ers une description du mécanisme d'assemblage du fusean miloiique à l'échelle moléculaire. múderine/scien- il sera difficile de décider quelles sont les séquences qui participent, et comment, à la fonction centromérique. Peut-être est-il bon de noter ici, encore, les résultats obtenus chez Chironomus pallidiviltatus, bien que cela nous éloigne des mammifères. Chez cet insecte, une structure ressemblant à celle trouvée chez $S$. pombe a été isolée et analysée en détail: des séquences répétées de divers types, orientées dans le même sens ou en sens inverse y sont présentes. Celte séquence hybride in silu une bande très fine des quatre chromosomes de l'organisme, à l'endroit correspondant à leurs centromères [3()].

\section{Pourquoi les régions centromériques ont-elles une structure compacte?}

L'une des caractéristiques principales des régions centromériques des chromosomes d'eucaryotes supérieurs est qu'elles constituent une structure compacte, l'hétérochromatine. Cela se traduit par l'apparition des bandes ( i des chromosomes de la métaphase dans ces régions.

Cette structure compacte se maintient pendant tout - ou presque le cycle cellulaire. Il s'agit de l'hétérochromatine constitutive, par contraste avec l’hétérochromatine facultative qui, comme son nom l'indique, n'est apparente qu'à certains moments ou endroits, un bon exemple étant représenté par l'inactivation du chromosome $X$ chez les mammifères placentaires [31]. A l'hétérochromatine est associée l'inactivation des gènes. Cette association est née d'observations diverses. En effet, chez la drosophile, par exemple, on sait que les régions centromériques contiennent beaucoup moins de gènes que les bras des chromosomes. En outre, lorsqu'un gène normalement présent dans l'euchromatine est transposé dans ou autour de la région centromérique, il subit le phénomène de position effect variegation (PEV) qui l'inactive dans certaines cellules. Il s'agit d'un phénomène qui, bien que seulement suspecté chez les mammifères [32], mérite qu'on s'y attarde un moment. Il a été découvert en 193() [33]. Dans l'exemple classique et très étudié du locus white, le gène, normalement exprimé en position distale du centromère du chromosome $\mathrm{X}$, est transposé au voisinage immédiat de celui-ci, avec pour conséquence une expression variable du locus selon les cellules, d'où un phénotype mosaïque de l'oil (rouge et blanc). Chaque cellule, au stade embryomaire, reçoit le signal d'inactivation ou non du gène et le transmet de façon stable et clonale. Il a été montré que cette inactivation variable correspond à une hétérochromatisation des séquences qui contiemnent le loms white. Le plus intéressant est qu'il existe une série de gènes suppresseurs ou amplificateurs du phénomène (près de 150) loci de ces types ont été répertoriés) qui peuvent étendre la structure hétérochromatique jusqu'a 8() bandes du centromère dans les chromosomes polytènes, soit environ sur 15()() kilobases [34, 35]. Plusieurs gènes suppresseurs/amplificateurs ont été clonés et séquencés. C'ertains d'entre eux tombent dans la catégoric des "haplo-suppresseurs, triploamplificateurs", ce qui veut dire que, présent en un seul exemplaire, le gène a un effet suppresseur sur le phénomène de variégation alors que trois exemplaires, ou plus, lui confèrent un effet amplificateur. Parmi ceux-i, l'un (Surar(3)7) code pour une protéine à doigts de zinc largement espacés; un autre (Surar(2)5) code pour une protéine associée exclusivement à l'hétérochromatine, IIPl. Cette protéine est très conservée, y compris chez les mammifères $[36,37]$. D'autres protéines modificatrices de la variégation des gènes ont été caractérisées ; elles sont "haplo-suppresseurs ou haplo-amplificateurs" sans qu'une dose triple, cette fois, ait un effet opposé. On pense qu’il s’agit généralement d'enzymes (une phosphatase pour Surar(3)6 et, semble-t-il, des enzymes sensibles au butyrate, inhibiteur de désacétylase des histones pour d'autres loci).

On voit donc que si les séquences d'AIN satellite semblent nécessaires pour assurer une structure hétérochromatique permanente dans les régions centromériques (la drosophile possède, elle aussi, des AI)N 
satellites dans ses régions centromériques), elles ne suffisent cependant pas pour y parvenir. Des protéines, en dehors des histones et non histones classiques, contribuent à l'établissement de la structure compacte de la chromatine et à l'inactivation des gènes placés directement au voisinage des régions centromériques. Pourtant, les choses se compliquent encore un peu puisque les gènes, normalement présents dans les régions centromériques des chromosomes de la drosophile, ont besoin de leur environnement hétérochromatique pour fonctionner normalement. Les en éloigner leur fait perdre leur activité, phénomène réversible comme pour le position-effect variegation [38].

On est évidemment impatient de savoir si des phénomènes analogues surviennent dans le génome humain. Pour le moment, nous en resterons à la supposition consensuelle, mais non établie, de l'absence totale de gènes dans les régions centromériques des chromosomes humains. Jusqu'à ce que le contraire soit montré ?...

La drosophile a fait beaucoup, c'est en tout cas le point de vue des auteurs de cette revue, pour notre compréhension future de la structure et du fonctionnement des centromères humains. Mais elle ne nous apprendra rien sur un autre aspect des séquences centromériques des mammifères: leur forte méthylation. Ce phénomène, qui affecte, chez les mammifères, la cytosine dans le doublet CpG a été corrélé positivement à l'inactivation de gènes $[39,40]$. Les ADN satellites sont fortement méthylés, mais cette méthylation est modulable selon les tissus, le tissu embryonnaire étant sous-méthylé ainsi que les cellules germinales [41-43]. On a même pu mettre en évidence une certaine décondensation de l'hétérochromatine centromérique au cours de la spermatogenèse sur le chromosome 9 , décondensation accompagnée d'une déméthylation concomitante des 5-méthyl cytosines des séquences d'ADN satellites. D'autres cas du même type ont également été rapportés dans la littérature sur des cellules de villosités choriales et dans des spermatocytes [44]. Bien $\mathrm{m} / \mathrm{s} n^{\circ} 3$ vol. 10 , mars 94 entendu, on n'a aucune idée de l'origine et de la signification de ce phénomène : est-ce pour activer des gènes supposés ne pas être présents dans cet environnement ?...

On peut ajouter que plusieurs expériences ont montré que la déméthylation de certains ADN satellites présents dans les centromères des chromosomes 1 et 16, par exemple, conduisait à une instabilité chromosomique se traduisant par des délétions et des translocations. Il a été suggéré que des protéines, interagissant spécifiquement avec les sites méthylés d'ADN satellites, étaient nécessaires pour la stabilisation de ces régions [45, 46].

Les variations de la méthylation des ADN satellites fait irrésistiblement penser à un autre phénomène épigénétique qui, lui, est bel et bien en action dans le génome des mammifères: l'empreinte parentale qui semble être induite par la méthylation au cours de la gamétogenèse ([47]). Bien que la méthylation de la cytosine en 5-méthyl-cytosine ne soit pas détectable chez la drosophile, l'empreinte parentale semble également y jouer un rôle, notamment au cours de la variégation décrite plus haut [48]. Il y a donc probablement beaucoup à apprendre de ce point de vue aussi des régions centromériques des chromosomes.

\section{Quelles anomalies de structure et/ou de fonctionnement?}

Il s'agit d'un chapitre difficile car les observations de comportements "anormaux" sont tellement nombreuses qu'il n'est pas aisé d'établir une frontière nette avec ce qui peut être considéré comme un fonctionnement "normal ». Ainsi, les fusions robertsoniennes* entre chromosomes acrocentriques qui sont communément observées chez l'homme, avec une prévalence de $1 / 1000$, ont parfois contribué à l'évolution des espèces en remaniant et en créant de nouvelles combinaisons du matériel génétique. Elles affectent préférentiellement les chromosomes acro-

* Fusions robertsonniennes: fusion de chromosomes acrocentriques par leurs centromeres. centriques qui, nous l'avons vu, ont l'occasion de se trouver "nez à nez" pendant la formation du nucléole au cours de la méiose. Les autres chromosomes sont également, quoique à une fréquence moindre, affectés par de telles fusions. Bien qu'encore insuffisamment documentées au niveau moléculaire, les données partielles font penser que les ADN satellites présents sont le siège de ces translocations. C'est ainsi qu'il a pu être montré que dans 24 translocations robertsoniennes, de types $\mathrm{t}(14 ; 21)$ et $\mathrm{t}(13 ; 14)$, les réarrangements chromosomiques qui en étaient la cause s'étaient produits préférentiellement dans l'ADN satellite III [49].

Si l'on veut parler d'anomalies, il faut donc avoir en tête la diversité structurale offerte à l'observateur. Normalement, le centromère permet, en association chez les mammifères avec le kinétochore, la ségrégation du matériel génétique au cours des mitoses et de la méiose. Les ADN satellites centromériques sont répliqués en fin de phase $S$. On a souvent évoqué cette réplication tardive (à noter que, chez la levure, cette réplication centromérique est au contraire précoce) pour expliquer pourquoi les régions centromériques restent attachées entre elles jusqu'au moment où cette réplication sera accomplie. Quoi qu'il en soit, lorsque les chromosomes se clivent pour rejoindre les deux pôles des cellules-filles, ils le font dans un ordre déterminé, invariable d'un type cellulaire à l'autre. Chez l'homme, les premiers à se séparer sont les chromosomes 18,17 , 2 , 10 et 12 , les derniers les chromosomes $21,22,13,14$ et $15[50]$.

La principale anomalie de fonctionnement supposée du centromère est celle qui conduit à des aneuploïdies. Celles-ci se produisent à la fois dans les cellules somatiques au cours des mitoses et dans les gamètes au cours de la méiose. Cet échec dans la ségrégation égale des chromosomes est appelée une non-disjonction, sans que l'on puisse expliquer pourquoi cet événement se produit.

L'observation que le chromosome X, dépourvu de constriction primaire et ressemblant à un chromosome acentrique, est fréquemment perdu dans 


\section{RÉFÉRENCES}

66. Rieder C.L, Ault JG, Eichenlaub-Ritter U, Sluder (;. Morphogenesis of the mito tic and meiotic spindle: conclusions obtained from one system are not necessarily applicable to the other. In: Vig BK, Kappas A, eds. Chromosome segregation and aneuploidy. New York: Springer-Verlag, 1993, (sous presse).

67. Simchen G, Hugerat Y. What determines whether chromosomes segregate reductionally or equationally in meiosis? Bio Essays 1993; 15: 1-8.

68. Prosser J, Frommer M, Paul C, Vincent PC. Sequence relationships of three human satellite DNAs. I Mol Biol 1986; 187 : 145-55.

69. Corneo G, Ginelli E, Polli E. Repeated sequences in human DNA. J Mol Biol 197()$; 33: 319-27$.

70. Manuelidis L. Chromosomal localization of complex and simple repeated human DNAs. Chromosoma 1978 ; 66: 23-32.

71. Mitchell AR, Gosden JR, Miller DA. A cloned sequence, $\mathrm{p} 82 \mathrm{H}$, of the alphoid repeated DNA family found at the centromeres of all chromosomes. Chromosoma $1985 ; 92$ : 369-77.

72. Cooper KF, Fisher RB, Tyler-Smith C. Structure of the pericentromeric long arm region of the human Y chromosome. J Mol Biol 1992; 228: 421-32.

73. Agresti A, Rinaldi G, Lobbiani A, Magnani 1, Di Lernia R, Meneveri R, Siccardi AG, (;inelli E. Chromosomal location by in situ hybridization of the human Sau.3A family of DNA repeats. Hum Genel $1987 ; 75: 326-32$.

74. Waye JS, Willard HF. Genomic organization and sequence definition of a class of highly repetitive tandem DNA. Proc Nall Acad Sci USA 1989; 86: 625()-4.

75. Gosden JR, Mitchell AR, Buckland RA, Clayton BP, Evans HJ. The location of four human satellite DNAs on human chromo somes. Exp Cell Res 1975; 92 : 148-58.

76. Grady DL, Ratliff RL, Robinson DL, McCanlies EC, Meyne J, Moyzis RK Highly conserved repetitive DNA sequences are present at human centromeres. Proc Nall Acad Sci USA 1992; 89: 1695-9.

77. Bloom K, Schulman I. Genetic dissection of centromere function. Mol Cell Biol 1993 ; 13: 3156-66. les lymphocytes humains en culture, a conduit à montrer que le centromère de ce chromosome se divise prématurément par rapport aux autres [51]. Ce phénomène peut être observé dans les cultures de lymphocytes provenant de femmes âgées plus fréquemment que dans ceux d'hommes d'âge comparable. Il se produit également in vivo. Le parallèle qui peut être fait avec l'âge maternel de survenue de grossesses trisomiques 21 a fait rechercher une corrélation entre division prématurée du centromère du chromosome 21 et trisomie 21 , sans résultat vraiment probant cependant.

Différentes autres hypothèses, parfois contradictoires, ont été proposées pour expliquer la non-disjonction chromosomique : certains, par exemple, ont prétendu que, dans la trisomie 21, un excès de chiasmas pouvait être à l'origine de nondisjonctions, alors que d'autres avançaient le contraire. Nous avons nousmêmes proposé une hypothèse fondée sur les variations de taille de blocs d'ADN satellite centromérique et de celles des kinétochores [52, 53 ]. D'une manière générale, cependant, on pense que le centromère est impliqué dans la non-disjonction des chromosomes et l'étude des cellules d'origine tumorale est très instructive de ce point de vue. Il est bien connu, en effet, que, dans certaines tumeurs, des réarrangements chromosomiques nombreux se produisent sans qu'il soit toujours facile, ou même possible, de dire en quoi ces remaniements sont primaires ou la conséquence de la nature cancéreuse des cellules. Ainsi, un certain nombre d'anomalies chromosomiques non aléatoires se produisent dans les adénocarcinomes colorectaux humains et il est remarquable que la plupart des réarrangements chromosomiques observés résultent de cassures localisées dans l'hétérochromatine juxtacentromérique, donc au niveau des ADN satellites [54].

Les observations impliquant le centromère dans les cancers ne s'arrêtent pas là. Dans une revue récente [55], il est rappelé que nombreux sont les cas de cancers où des chromosomes multicentriques sont créés. On trouve de tels exemples, également, dans des cellules humaines normales, comme dans le cas d'un chromosome dicentrique dic $(13 ; 13)$ affectant le chromosome 13 [56]. Généralement, ces centromères surnuméraires sont inactivés, comme cela a été aussi observé sur le chromosome 2 humain où subsiste un centromère ancestral simien inactivé résultant vraisemblablement de la fusion de deux chromosomes de singe $[57,58]$. Il est intéressant d'étudier ces cas de centromères inactifs surnuméraires car ils perdent deux propriétés essentielles que possèdent les centromères actifs : (1) les centromères inactifs sont, en effet, séparés bien avant les centromères actifs (entre le début et la fin de la prophase) ; ces derniers, quant à eux, sont maintenus attachés jusqu'à la méta-anaphase. Cette différence s'accompagne d'un changement du moment de la réplication qui, de la phase $\mathrm{S}$ tardive pour les séquences d'ADN centromériques vraies, passe à la phase $\mathrm{S}$ précoce. Ils gardent, cependant, une caractéristique des centromères actifs, une certaine "courbure»; (2) ils ont également perdu leur capacité de lier les protéines du kinétochore.

Il existe également des cas très intéressants où plusieurs centromères sont actifs simultanément. Dans ce cas, les centromères surnuméraires ont alors conservé les propriétés de vrais centromères, ce qui conduit à des anomalies de la ségrégation des chromosomes.

On peut noter aussi les anomalies de méthylation des $\mathrm{ADN}$ satellites centromériques chez les patients atteints du syndrome ICF qui combine une immunodéficience variable, une instabilité de l'hétérochromatine centromérique, et des anomalies faciales [46]. Au point de vue moléculaire, ces anomalies correspondent à un déficit de méthylation des $\mathrm{ADN}$ satellites qui pourrait être à l'origine d'une instabilité de l'hétérochromatine centromérique, comme cela a été noté plus haut. Citons, enfin, la variante de sclérodermie appelée syndrome de CREST (calcinosis, Raynaud phenomenon, cesophageal dismotility, sclerodactyly, telangiectasia) car il a été découvert que les patients produisaient des anticorps contre des antigènes spé- 
cifiques des kinétochores [59]. ('est grâce à ces anticorps de patients que la structure du kinétochore et la nature biochimique de ses constituants ont pu être particllement élucidées.

\section{Conclusion et perspectives}

la panoplie de méthodes utilisées pour étudier les centromères de mammifères n'a pas permis, pour le moment, de répondre précisément à un certain nombre de questions concernant leur structure moléculaire et leur fonctionnement.

On pense aujourd'hui que les $\mathrm{ADN}$ satellites, constituants universels des centromères che\% les eucarvotes supérieurs, jouent certainement un rôle dans leur fonction, en dépit de leur extraordinaire diversité de structure (séquences, unités de répétition, abondance). Mais dès que l'on ouvre une piste pouvant expliquer éventuellement leur comportement lié à la fonction centromérique elle-même, on bute devant cette diversité. Par exemple, la méthylation qui a été invoquée pour expliquer la condensation de l'hétéro chromatine centromérique chez les mammifères, ne peut l'être chè la drosophile dont les centromères présentent, en outre, d'autres aspects particuliers

Cette diversité ne décourage cependant pas les tentatives de généralisation. Ainsi, on a proposé, dans le cas de l'ADN satellite de la souris, que le caractère compact de la chromatine centromérique serait dî̀ la propriété intrinsèque de sà séquence à présenter une courbure stable de l'ADN. Cette courbure induirait une condensation de la chromatine correspondante $[6(0), 61]$. Plusieurs autres $\mathrm{ADN}$ satellites présentent la même propriété, parmi lesquels ceux du rat, alpha du singe vert d'Afrique [62] et du xénope [63]. (n a même montré que cette courbure - ou pliure (intrinsic bend) - était caractéristique de l'élément CDE I du centromère de $S$. cerevisiae lié à une protéine spécifique (.ppl1 (centromere binding factor 1), le complexe CI)E I/Cipfl réglant les conditions optimales de la fonction centromérique [64].

Il est probable qu'au cours de l'évolution, comme dans le cas d'un autre système très complexe, celui de l'assemblage du fuseau mitotique $[65,66]$, certains aspects de la fonction soient universels alors que d'autres se seraient diversifiés selon les organismes. I.es subtilités de fonctionnement déjà mises en évidence dans un système "simple" comme celui de la levure nous laissent augurer que, lorsque les éléments essentiels qui permettent la fonction centromérique chez l'homme seront reconnus, le système sera encore loin d'avoir livré tous ses secrets. Rappelons seulement ici que la fonction centromérique s'exerce différemment selon le stade de la méiose. Il faudra bien montrer, alors, quelles sont les caractéristiques propres aux centromères qui conduisent à une ségrégation réductionnelle ou équation- nelle au cours des divisions méiotiques I et II respectivement. (iageons que là encore $S$. cerevisiae nous aura ouvert la voie [67]

\section{Surnmary}

The centromeres of the manmalian chromosomes

The secrecy of the nature of the centromere-kinetochore complex of mammals is beginning to be betrayed. One can already firmly suggest that, among the other satellite DNAs which are a subset of the constituants of the human centromeric regions, the alpha satellite is probably contributing to the function of the centromere. The physical structure of the centromere-kinetochore complex is variable from one chromosome to the other and, moreover, prone to extreme polymorphism. Interactions between DNA and some of the proteins of the complex have been demonstrated. One still does not know, however, why centromeric regions remain compact all along the cell cycle, why they are restricted in recombination and if they contain any gene. Centromere dysfunction is associated with a number of pathologies in man (aneuploidies, cancers...). A number of important questions concerning their structure and function remain, however, unanswered. 